\title{
Thioguanine Therapy in Inflammatory Bowel Diseases. A Practical Guide
}

\author{
Femke Crouwel $^{1}$, Melek Simsek ${ }^{1}$, Chris J.J. Mulder ${ }^{1}$, Hans J.C. Buiter ${ }^{2}$, Nanne K. de Boer ${ }^{1}$
}

1) Department of

Gastroenterology and

Hepatology, AGEM Research

Institute, Amsterdam

University Medical Centre,

Vrije Universiteit Amsterdam,

Amsterdam;

2) Department of Clinical

Pharmacology and Pharmacy,

Amsterdam University

Medical Centre, Vrije

Universiteit Amsterdam,

Amsterdam, the Netherlands

Address for correspondence:

Femke Crouwel, MD

Department of

Gastroenterology and

Hepatology, AGEM Research

Institute, Amsterdam

University Medical Centre,

Vrije Universiteit Amsterdam,

Amsterdam, the Netherlands

f.crouwel@amsterdamumc.nl

Received: 30.06.2020

Accepted: 13.10.2020

\section{ABSTRACT}

Thiopurine-derivates azathioprine and mercaptopurine are frequently used to maintain remission in inflammatory bowel diseases (IBD). Despite their efficacy, more than $50 \%$ of patients discontinue therapy, mainly due to the development of adverse events. Thioguanine is an alternative thiopurine and has been conditionally licensed in The Netherlands as IBD treatment for patients after conventional thiopurine therapy failure. In this review we will provide practical information on initiating and maintaining thioguanine therapy in IBD and provide information concerning safety issues and future perspectives. The thioguanine toxicity profile is relatively mild and the reported incidence of nodular regenerative hyperplasia related to thioguanine use seems comparable to conventional thiopurines and the background incidence in IBD patients. Routine monitoring of laboratory parameters and adverse events is recommended, comparable to the monitoring of patients on conventional thiopurine therapy.

Key words: inflammatory bowel diseases - thioguanine - guideline - drug-related side effects and adverse reactions.

Abbreviations: AZA: azathioprine CD: Crohn's disease; EBV: Epstein-Barr Virus; HGPRT: hypoxanthineguanine phosphoribosyl transferase; HLH: hemophagocytic lymphohistiocytosis; HR: hazard ratio; IBD: inflammatory bowel diseases; ITPase: inosine triphosphate pyrophosphohydrolase; MP: mercaptopurine; NRH: nodular regenerative hyperplasia; OR: odds ratio; TDM: therapeutic drug monitoring; TG: thioguanine; TNF: tumor necrosis factor; TPMT: thiopurine methyltransferase; UC: ulcerative colitis; WBC: white blood cell count; XO: xanthine oxidase; 5-ASA: 5-aminosalicylates; 6-thio-ITP: 6-thiosine triphosphate; 6-MMP: 6-methylmercaptopurines; 6-TGN: 6-thioguanine nucleotides.

\section{INTRODUCTION}

Given the relapsing clinical course ofCrohn's disease (CD) and ulcerative colitis (UC), together known as inflammatory bowel diseases (IBD), maintenance therapy is commonly needed to maintain remission. There are various drugs used for this reason including conventional thiopurines as azathioprine (AZA) and mercaptopurine (MP) $[1,2]$. Despite their effectiveness, $50 \%$ of patients discontinue thiopurine therapy, mainly due to the development of adverse events [3]. When adverse effects develop or therapy fails for another reason, an option may be switching to a third thiopurine-derivate: thioguanine (TG).

This practical review is an update of our earlier proposed expert based guideline in 2010 as larger studies have become available in this field since then [4]. Moreover, TG received a conditional license for the treatment of IBD in the Netherlands in 2015 and can be prescribed to patients who previously failed conventional thiopurine therapy due to a lack of response or adverse effects [5].

\section{METABOLISM OF THIOGUANINE}

Due to a different metabolic pathway, theoretically, TG has potential advantages as compared to MP or AZA. One of the main differences is the direct conversion into the pharmacological active 6-thioguanine nucleotides (6-TGN) by hypoxanthineguanine phosphoribosyl transferase (HGPRT) without the formation of potential hepatotoxic 6-methylmercaptopurines (6-MMP) (Fig. 1) [6]. Another difference is the less central role 


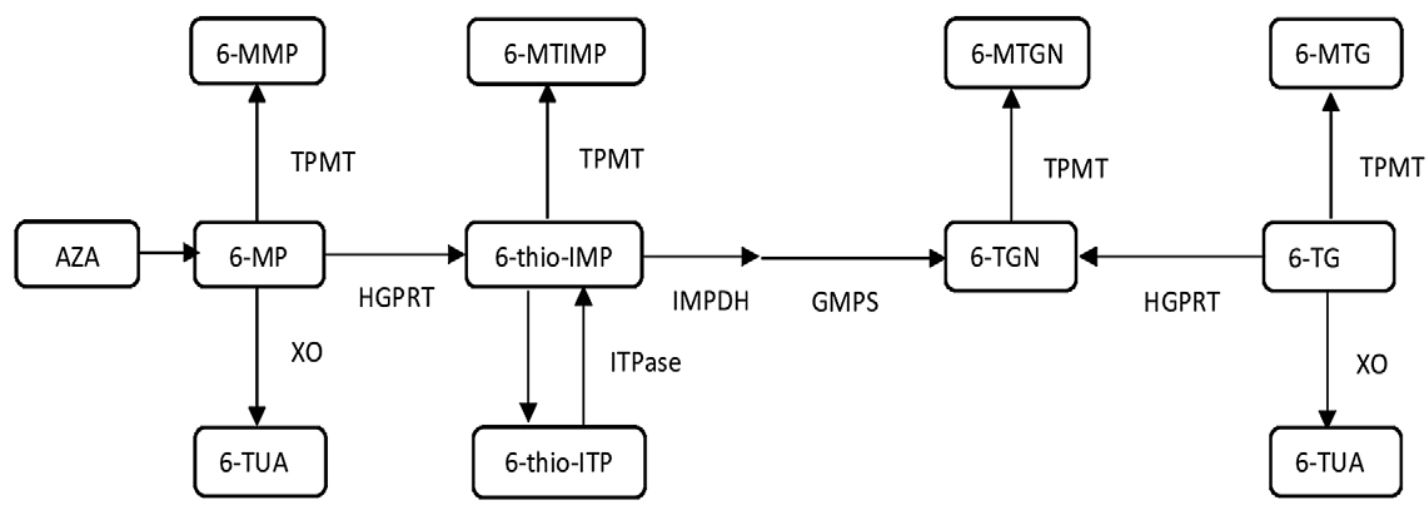

Fig. 1. Simplified thiopurine metabolism scheme. Azathioprine (AZA) is converted to 6-mercaptopurine (6-MP). Thiopurine methyltransferase (TPMT) methylates 6-MP into the potential hepatotoxic 6-methylmercaptopurine (6-MMP) and xanthine oxidase (XO) can catabolize 6-MP into 6-thiouric acid (6-TUA). Hypoxanthine-guanine phosphoribosyl transferase (HGPRT) converts 6-MP into 6-thiosine monophosphate (6-thio-IMP). 6-thio-IMP can be further metabolized into the active 6-TGN. 6-TGN may also be methylated by TPMT leading to 6-methylthioguanine nucleotides (6-MTGN). In a cycle 6-tio-IMP is eventually phosphorylated to 6-thiosine triphosphate (6-thio-ITP) and ultimately back to 6-thio-IMP due to inosine triphosphate pyrophosphatase (ITPase). 6-thioguanine (6-TG) is directly converted into 6-TGN but may also be methylated by TPMT into 6-methylthioguanine (6-MTG) or catabolized into 6-TUA by XO.

of thiopurine methyltransferase (TPMT) in the metabolism of TG, in contrast to the importance of this enzyme in the metabolism of AZA and MP. Unfortunately, patients treated with AZA or MP can have a preferential shunting towards 6-MMP or 6-TGN formation depending on the activity of TPMT $[7,8]$. Although TG can also be converted by TPMT or xanthine oxidase (XO), this effect is limited compared with conventional thiopurines, resulting in a larger amount of TG available for conversion into 6-TGN. During conventional thiopurine therapy, diminished activity of the enzyme inosine triphosphate pyrophosphohydrolase (ITPase) has been associated with the development of adverse events such as rash, pancreatitis and flu-like illness possibly due to an accumulation of 6-thiosine triphosphate (6-thio-ITP) [9]. TG is not a substrate for ITPase, therefore this metabolic step is bypassed and 6-thio-ITP does not accumulate in ITPase deficient patients [9].

In summary, the apparent metabolic advantages of TG compared to AZA or MP are the more direct conversion into 6-TGN without potentially rate limiting steps, less influence of the enzyme TPMT, the absence of formation of potential hepatotoxic 6-MMP, less side metabolites in general and no side-effects induced by ITPase.

\section{CONVENTIONAL THIOPURINES AND THIOGUANINE THERAPY}

Conventional thiopurines, AZA or MP, are in general not prescribed as induction therapy in the active phase of CD or UC, but if a more severe disease course is expected they can be co-administrated together with an induction course of corticosteroids. However, in steroid-dependent $\mathrm{CD}$ they are prescribed as maintenance drugs of choice [1]. 5-aminosalicylates (5-ASA) are the primary drugs of choice to induce and maintain remission in UC. In case of intolerance or drug resistance, thiopurines may be administered for maintenance of remission and steroid sparing, respectively
[2]. In addition to their role as first-line immunomodulators, thiopurines are also prescribed in combination with anti-tumor necrosis factor (anti-TNF), especially infliximab, to induce and maintain remission in patients with an inadequate response to conventional therapy, resulting in higher rates of clinical remission and better mucosal healing $[1,10]$. Besides the higher rates of clinical remission with combination therapy, the randomized control SONIC trial among biological and immune modulator naïve $\mathrm{CD}$ patients also demonstrated that less patients developed antibodies in the combination therapy group compared to patients with monotherapy infliximab $(0.9 \%$ vs $14.6 \%)$ and there was a significantly lower median through level of serum infliximab in the latter [10]. Also, in patients previously treated with an anti-TNF, not only in those who experience immune-mediated loss of response, thiopurines or methotrexate may be used in combination with the prescribed second anti-TNF [11]. There are studies which suggest that patients who have a loss of response on monotherapy thiopurines do not benefit from the continuation of thiopurines once biologic therapy is begun, although hard evidence is lacking and lower immunogenicity should also be considered in these patients $[1,12,13]$. In the short-term, combination therapy seems safe since the SONIC trial showed that there was no significant difference with regard to serious adverse events or infection after 1 year combination therapy. In the long-term however, there seems to be an increased risk of opportunistic [Hazard ratio (HR), 1.96] and serious (HR, 1.23) infections compared with monotherapy antiTNF [14]. In addition, a case-control study showed that the use of two or more immunosuppresants (corticosteroids, AZA/MP or infliximab) gives an odds ratio (OR) of 14.5 for opportunistic infections compared with an OR of 2.9 for monotherapy [15]. So, in clinical practice the added benefits of combination therapy should always be balanced against the potential increase in adverse events. There is no added value of combining vedolizumab, ustekinumab and tofacitinib with a thiopurine [16]. 
When initiating a thiopurine the use of MP may be preferred as initial therapy rather than AZA, based on several rechallenge studies [17-19]. These studies showed that up to $68 \%$ of patients intolerant to AZA were able to tolerate MP [1719]. If therapy with a conventional thiopurine fails or adverse effects develop, management can include dose reduction, combining low dose thiopurine with allopurinol and assessing metabolite levels [i.e. therapeutic drug monitoring (TDM): measuring 6-TGN and 6-MMP levels in erythrocytes)] or switching to the alternative thiopurine TG.

When patients experience side-effects related to elevated 6-MMP levels, we discuss two possible strategies: to start with the combination azathioprine/allopurinol therapy or to switch to monotherapy TG. Due to the lower pill burden the latter is often preferred [20]. Also, patients who still experience mild side-effects after a rechallenge with MP can benefit from a switch to TG $[21,22]$. Side effects during TG therapy tend to be different than those experienced with AZA or MP and patients intolerant to conventional thiopurines uncommonly have recurrence of these adverse effects with TG [21,22]. A key setting in which it is recommended to switch to TG therapy is a history of pancreatitis during conventional thiopurine therapy, as multiple studies have demonstrated that previous thiopurine-induced pancreatitis did not reoccur with TG treatment $[21,23]$.

\section{EFFECTIVENESS AND LONG-TERM SAFETY OF THIOGUANINE}

Since TG is a commonly used drug in the treatment of acute nonlymphocytic leukemia and acute lymphoblastic leukemia and approved by the EMA (European Medicines Agency) and the FDA (Food and Drug Administration) for this intent, it is available in most countries as off-label IBD treatment. Moreover, in the Netherlands, TG (Thiosix ${ }^{\circledR} 10$ and 20 mg tablets) has been conditionally licensed as a certified IBD treatment since 2015 for patients who previously failed conventional thiopurine therapy due to lack of response or adverse effects [5]. Besides the Netherlands more national guidelines, for example the guideline of New Zealand, mentioned TG as an alternative for conventional thiopurines, even though it is not brought up in international IBD guidelines.

A systematic review about the efficacy of TG treatment after AZA/MP failure showed clinical improvement, defined as a decrease in symptoms scales or the opportunity to cease or clinically significantly decrease corticosteroids without disease relapse, in 65\% [24]. Almost all patients in the included studies were treated with monotherapy TG or used TG in combination with steroids, cyclosporine or 5-ASA (5-aminosalicylic acid); only 18 out of 353 included patients were treated with combination therapy. The effectiveness found in this systematic review roughly corresponds to available literature regarding the efficacy of AZA or MP, despite most included patients experienced intolerance or inadequate response to previous AZA or MP therapy [24-26]. The type of IBD seems to have no influence on the effectiveness of TG. Studies revealed no significant difference in the response rate between $C D$ and UC patients and both patient groups benefited from therapy with TG [24, 27].
The long-term safety of TG therapy was investigated in a retrospective study by Simsek et al. [27]. This study included 274 IBD patients who previously failed therapy with conventional thiopurines and were now treated with a median dosage of $20 \mathrm{mg}$ TG. This study demonstrated a median duration of TG use of 51 months (IQR: 36-89) with 1,567 patient-years of follow up [27]. In this retrospective cohort 112 patients (41\%) reported a total of 186 adverse events during 1,567 patient-years of follow-up and the majority (65\%) of adverse events was graded as mild according to the CTCEA. Intolerable severe adverse events leading to withdrawal of therapy were reported in $11 \%$, mainly in patients who recently started TG therapy [27]. In addition, a smaller retrospective study, which included 54 IBD patients who also failed previous therapy with conventional thiopurines, concluded that the efficacy and side-effects of TG [mean dose $27 \mathrm{mg} / \mathrm{d}$ (range 20-40 mg/d)] were comparable to AZA/MP and that the safety data are reassuring [21]. Although longer follow-up safety data for conventional thiopurines are available and both drugs have never been head-to-head compared, it appears that these data are, to some extent, comparable. It must be said, however, that all patients in the retrospective TG cohort previously failed conventional thiopurines $[21,27]$.

The effectiveness of combination therapy with anti-TNF and TG, instead of AZA/MP, is not yet determined. One could speculate that TG has the same effect on immunogenicity as AZA/MP, certainly since methotrexate (another immune modulator) demonstrated similar effects of decreasing antibodies to infliximab and increasing infliximab trough levels, but firm evidence is lacking [28].

\section{DOSING, INITIATION AND FOLLOW-UP OF THIOGUANINE THERAPY}

Formal large dose-ranging studies are lacking, but in the Netherlands a dosage of approximately $0.2-0.3 \mathrm{mg} /$ $\mathrm{kg}$ bodyweight per day is prescribed, leading to a standard dosage of $20 \mathrm{mg}$ per day. This dosing regime is tolerated by up to $80 \%$ of patients who were intolerant for preceding conventional thiopurines [24]. Moreover, a systematic review demonstrated that the two studies with a starting dose of 20 mg per day had the highest effectiveness rate, possibly because a lower dosage leads to better tolerability and could therefore contribute to longer usage and subsequent higher efficacy [24]. It is recommended that the dosage should not exceed 25 mg per day since a higher dosage has been associated with an increased risk of drug-induced liver injury, especially nodular regenerative hyperplasia (NRH) [29-35].

Thioguanine seems to have a clinically faster onset of action than AZA/MP and there are studies which demonstrated that some patients have a clinical response after 4 weeks $[36,37]$. However, just as with AZA/MP, sometimes it can take multiple weeks or months before treatment with TG is effective, making it less suitable for induction of response.

In general, before prescribing a thiopurine (AZA, MP or TG), the immunization status against certain infections (e.g. hepatitis $B$, hepatitis $C$ (on indication)) should be checked to prevent reactivation. The usefulness of serologic testing for Epstein-Barr Virus (EBV) before the initiation of any 
thiopurine, and subsequently avoiding them in EBV IgG negative IBD patients, is still debated. Thiopurine use has been associated with potentially fatal and severe EBV primary infections and post infectious lymphoproliferative disorders although the incidence seems to be low [38]. The CESAME (Cancers et Sur-risque Associé aux Maladies Inflammatoires Intestinales en France) study found an incidence of postmononucleosis lymphomas of 0.1 per 1000 patients years rising up to 3 per 1000 patients years in young, seronegative males. Although a study performed in a pediatric population found that 4 of the 5 patients who developed hemophagocytic lymphohistiocytosis (HLH) had a primary EBV infection and were treated with a thiopurine, this still represented an incidence rate of 0.2 per 1000 patients years $[38,39]$. Moreover, in the United States more than $89 \%$ of adults are seropositive for EBV and, according to a retrospective analysis, approximately $45 \%$ of seronegative IBD patients who underwent a screening before initiation of therapy still received thiopurine [40, 41]. Given this high exposure to EBV in adulthood and the low incidence of HLH and post-mononucleosis infections there are articles who doubt the usefulness and cost-effectiveness of serologic testing for EBV before thiopurine initiation [4143]. This uncertainty about the usefulness of EBV screening also emerged in our hospital, consequently leading to an ambiguous policy.

After prescribing a thiopurine safety monitoring must be performed on regular basis in all patients. We recommend to measure liver tests (alanine aminotransferase, aspartate aminotransferase, alkaline phosphatase and gammaglutamyltransferase), C-reactive protein and complete blood count including white blood cell count (WBC) at baseline and after 1, 2, 4, 8 and 12 weeks and after that every 3-4 months during maintenance therapy, routinely performing a liver biopsy is no longer standard of care in our center (Fig. 2). Transient elastography (FibroScan) plays no role in the safety monitoring of thiopurines $[44,45]$. When there is a twofold rise of at least one liver test and if this rise is possibly related to TG use the drug must be discontinued and a rechallenge may be discussed after normalization of liver tests.

Although leukopenia is quite uncommon in TG users, when it does occur and there is a leukocyte counts between 1.0 and $3.5 \times 10^{9} / 1$ the TG dose should be reduced, and administration has to be stopped when the leukocyte count is lower than 1.0 $\mathrm{x} 10^{9} / \mathrm{l}$. We recommend performing an abdominal ultrasound followed by a liver biopsy in patients with persisting liver test abnormalities (especially an elevated alkaline phosphatase level) and/or a persisting low platelet count $\left(<150 \times 10^{9} / 1\right)$ since these are associated with (non-cirrhotic) portal hypertension and NRH (Fig. 2).

\section{THERAPEUTIC DRUG MONITORING}

During conventional thiopurine therapy, TDM can be used to explore why patients are intolerant or resistant to therapy, for dose adjustment but also to predict dose-dependent adverse events such as hepatotoxicity (due to elevated 6-MMP levels) or myelotoxicity [46]. Myelotoxicity is mostly ascribed to high concentrations of 6-TGN; however, extremely high 6-MMP concentrations are also associated with myelotoxicity, assumingly by the inhibition of de novo purine synthesis [7, 8]. In clinical practice we aim at 6-TGN levels between 300 and $600 \mathrm{pmol} / 8 \times 10^{8} / \mathrm{lRC}$, measured with the method of Dervieux since this range is associated with a higher chance of effectiveness [47]. It is important for clinicians to be aware of the kind of method, Lennard or Dervieux, which is used to determine the metabolites, since the erythrocyte 6-TGN concentration is higher in the Dervieux method compared to the Lennard method [48].

In contrast to conventional thiopurines, data on the utility of TDM during TG treatment are sparse and the correlation between measured 6-TGN concentration and effectiveness of TG therapy is not yet elucidated [47, 49-51]. A recent study concluded that 6-TGN levels were higher in the clinical responders and suggested a rounded cut-off value for effectiveness of therapy $\geq 700 \mathrm{pmol} / 8 \times 10^{8} / 1 \mathrm{RBC}$ (measured according to Dervieux method). However, more research is mandatory before this cut-off value may be considered in clinical practice [27]. It must be emphasized that TG is converted into relatively high 6-TGN levels without inducing myelotoxicity, which would be the case with high levels of 6-TGN during AZA/MP therapy [52].

Myelotoxicity during treatment with low-dose TG is rare and when it is encountered, it is often transient and most patients do not require cessation of therapy [21, 37].

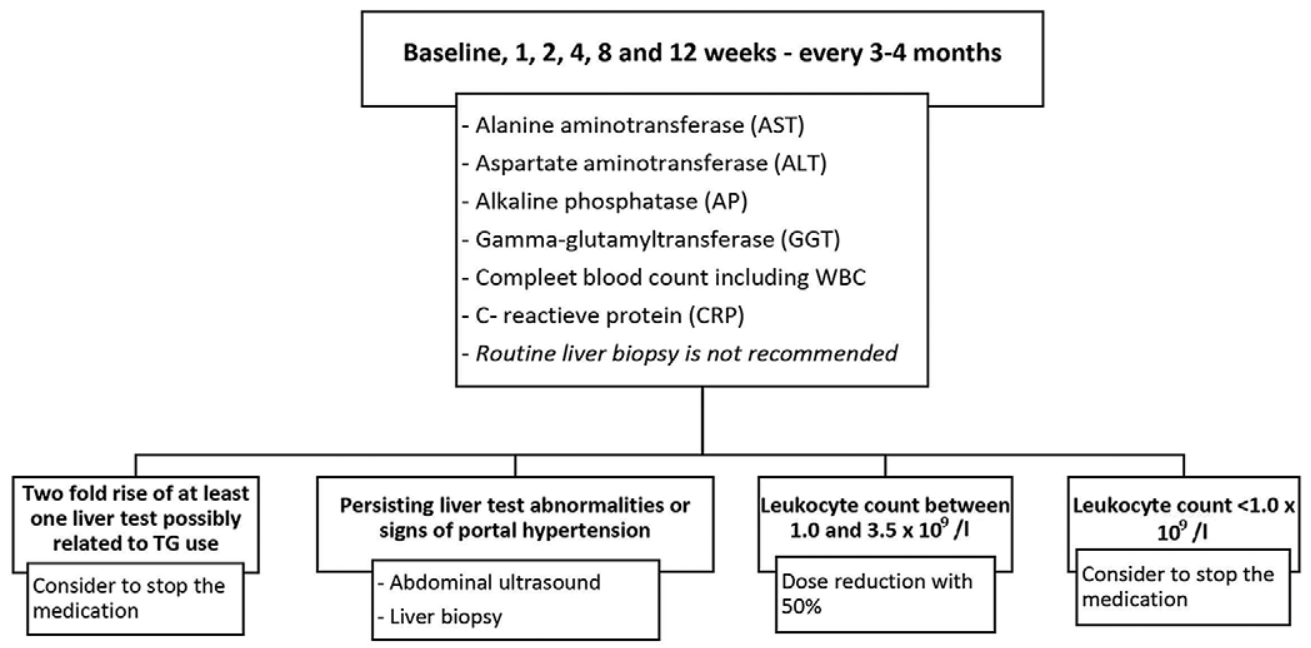

Fig. 2. Flowchart of controls in thioguanine therapy and how to act in case of abnormalities. 
Interestingly, in a retrospective study $(n=266)$ a positive correlation between 6 -TGN concentration and WBC or platelet count was demonstrated, in contrast to the negative correlation between 6-TGN and WBC in AZA or MP users [53]. This may implicate that the effect of TG on bone marrow function is limited and underlines the clinical observation that leukocytopenia is quite uncommon in TG users. This may suggest that TG might also be indicated for AZA/MP induced leukopenia as an escape drug. Nevertheless, there are also two cases in the literature describing severe pancytopenia during TG treatment due to extremely elevated 6-TGN levels caused by TPMT deficiency $[54,55]$.

Also during conventional thiopurine therapy, diminished TPMT enzyme activity could lead to severe myelotoxicity which can be prevented by initiating thiopurine therapy in a lower dosage [56]. However, solely $25 \%$ of the occurred leukopenia during AZA or MP therapy can be ascribed to a TPMT deficiency which still leads to an ongoing debate regarding the application of preemptive TPMT genotyping before initiating therapy [57]. Even though, a recent study concluded that, in conventional thiopurine therapy, this personalized strategy of preemptive TPMT genotyping before initiating thiopurines seems to be a cost-neutral and safe option [58]. Considering the metabolism of TG, it seems likely that diminished TPMT activity is less frequently associated with myelotoxicity during TG therapy but, besides two case reports, less is known about the gene-drug-interaction between TG and TPMT in IBD. More studies need to be performed to elucidate the optimal approach with regard to preemptive TPMT genotyping, TDM and blood checks during TG treatment.

In our center we do not measure TPMT status before initiating low dose TG therapy, which is in line with the clinical European Crohn's and Colitis Organisation (ECCO) guidelines, although other hospitals perform preemptive TMPT genotyping before starting with TG to prevent severe myelotoxicity as observed in case-reports $[54,55]$. Therapeutic drug monitoring is also not performed routinely in clinical practice in our center and we primarily measure metabolites in patients with a non-response to TG to rule out non-compliance. We perform frequent blood checks, which also include hematological parameters, to check for myelotoxicity.

\section{PREGNANCY}

Conventional thiopurine exposure throughout conception and pregnancy is considered to be safe [59-61]. Since 6-TGNs are the end metabolites of TG and AZA/MP, one may assume that these three drugs have the same effect on pregnancy outcome. There is a lack of sufficient data regarding the safety during pregnancy and teratogenicity of TG. There is a small study which shows reassuring outcomes and suggests safe use of TG during pregnancy, but all these seemingly encouraging data are based on a limited number of patients (13 patients, 19 pregnancies) [62]. Further short- and long-term cohort studies are required to confirm the safety in pregnant women. In our center we discuss each patient in a case by case manner, and after a thorough consultation by the gynecologist, if the continuation of TG during pregnancy to maintain remission and prevent a flare-up is advisable.

\section{NODULAR REGENERATIVE HYPERPLASIA}

One of the feared complications during TG therapy is the occurrence of sinusoidal obstruction syndrome and especially $\mathrm{NRH}$ which is not always reflected in changes of liver function tests $[33,63,64]$. However, in contrast to earlier observations, the development of TG induced NRH appears to be doserelated. A recent systematic review which included 42 articles about the hepatotoxicity of 6-TG showed that NRH occurs in $14 \%$ of patients treated with a daily dose of approximately 0.6 $\mathrm{mg} / \mathrm{kg}$ and rarely occurs at low cumulative doses (i.e. $0.2-0.3$ $\mathrm{mg} / \mathrm{kg}$ ) [29]. Secondly, NRH is not specifically correlated with TG, but is also common with conventional thiopurines and IBD itself [29, 33, 65-67]. Furthermore, it had been observed that NRH rarely led to symptoms of portal hypertension or liver transplant and was clinically insignificant in most patients $[68,69]$. These findings were supported by a recent study which demonstrated that vascular liver abnormalities of any degree were commonly observed in long-term TG treated IBD patients, but these were rarely progressive and of limited clinical relevance [70].

There are indications that $\mathrm{NRH}$ is potential reversible, demonstrated by a normalization of alkaline phosphatase and platelet count, a reduction in the hepatic venous pressure gradient after discontinuation of TG therapy and symptoms of non-cirrhotic portal hypertension also appeared to resolve in one-third $[71,72]$. Longer follow up data after discontinuation of such patients are needed.

Due to these new insights we do not routinely perform ultrasonography or liver biopsies in our patients with TG anymore but conduct these only in case of a high level of suspicion: after an abnormal abdominal ultrasound, in symptomatic patients with symptoms of portal hypertension (e.g. platelet count $<150 \times 10^{9} / 1$, varices, ascites, hepatic encephalopathy) or persisting liver test abnormalities (especially an elevated alkaline phosphatase level) without another plausible explanation. The FibroScan has little added value in the safety monitoring of thiopurines since there is no fibrosis in patients with NRH. Moreover, the study by Laharie et al. [44] demonstrated that the results of the FibroScan do not correlate with the portal or perisinusoidal fibrosis on biopsy and there also seems to be no correlation between liver stiffness and portal hypertension. These findings were confirmed by Meijer et al. [45] who also did not find a significant difference in liver stiffness between patients treated with thiopurines with biopsy confirmed abnormalities and patients without.

\section{CANCER RISK}

The use of AZA/MP is associated with a higher risk of the development of lymphoproliferative disorders, but this increased risk diminished after discontinuation of therapy [73]. Furthermore, there is an increased risk of the development of non-melanoma skin cancer according to a meta-analysis ( 8 studies, $n=60,351$ ) involving IBD patients using AZA/ MP [74]. Mutagenic properties have been described to TG as well and the reported increased risk of cancer during therapy with AZA/MP may also apply to TG [75]. One cohort 
study, including 274 TG-using IBD patients (median dose 20 $\mathrm{mg} / \mathrm{d}$ ) with 1567 patient-years of follow-up, showed that 9 patients $(3.3 \%)$ developed moderate malignancies (i.e. 5 nonmelanoma skin cancers, 2 melanoma skin cancers and 2 solid organ cancers). Two patients $(0.7 \%)$ developed severe graded malignancies (i.e. 1 non-Hodgkin lymphoma and 1 Merkel cell carcinoma) leading to a discontinuation of TG [27]. Patients need to be informed about the probable increased risk of malignancy before therapy is initiated and the importance of daily sun protective measures and 'self-skin exams', especially in countries with a high number of sunshine hours since the risk for non-melanoma skin cancer is related to cumulative sunlight exposure [76].

\section{FUTURE PERSPECTIVES}

Recent discoveries have provided additional information about the metabolism of TG. In contrast to AZA/MP, the gut microbiome is able to convert TG to the therapeutically effective 6-TGN [77]. These findings were confirmed in Winnie mice which experienced a rapid improvement of the colitis in regions of the colon with direct contact to rectally administrated TG; this was in contrast to mice treated with topical MP [78]. These data suggests that local delivery of TG could lead to a conversion of TG to 6-TGN by the microbiome without the requirement of host metabolism, leading to an additional mode of action of local immunosuppression. Following these findings controlled-release oral formulations of TG are being developed and even a few patients were treated with daily TG enemas or suppositories with a rapid treatment response and with low systemic bioavailability of 6-TGN [79]. Although future studies are needed to confirm these findings, they pave the way for therapy with TG enemas or oral delayed-release preparations which, in contrast to the current situation, will permit a more rapid therapeutic action of TG with potential avoidance of unwanted systemic adverse effects.

\section{CONCLUSIONS}

Thioguanine is formally registered for IBD patients in the Netherlands who previously failed conventional thiopurine therapy due to lack of response or adverse effects. The TG toxicity profile is relatively mild and the reported incidence of NRH related to TG use seems comparable to conventional thiopurines and the background incidence of NRH in IBD patients. Routine monitoring of laboratory parameters and adverse events is recommended, comparable to the monitoring of patients on conventional thiopurine therapy.

Conflicts of interest: N.K.B. has served as a speaker for AbbVie and MSD and has served as consultant and principal investigator for TEVA Pharma BV and Takeda. He has received a (unrestricted) research grant from Dr. Falk, TEVA Pharma BV, MLDS and Takeda. The other authors declare no conflicts of interest.

Authors' contributions: F.C. conceived the study. F.C. drafted the first version of the manuscript. M.S., C.J.J.M., N.K.B. and H.J.C.B. critically revised the manuscript. All authors approved the final version to be published and agree to be accountable for all aspects of the work.

\section{REFERENCES}

1. Torres J, Bonovas S, Doherty G, et al. ECCO Guidelines on Therapeutics in Crohn's Disease: Medical Treatment. J Crohns Colitis 2020;14:4-22. doi:10.1093/ecco-jcc/jjz180

2. Harbord M, Eliakim R, Bettenworth D, et al. Third European Evidencebased Consensus on Diagnosis and Management of Ulcerative Colitis. Part 2: Current Management. J Crohns Colitis 2017;11:769-784. doi:10.1093/ecco-jcc/jjx009

3. Jharap B, Seinen ML, de Boer NK, et al. Thiopurine therapy in inflammatory bowel disease patients: analyses of two 8-year intercept cohorts. Inflamm Bowel Dis 2010;16:1541-1549. doi:10.1002/ibd.21221

4. Seinen ML, van Asseldonk DP, Mulder CJ, de Boer NK. Dosing 6-thioguanine in inflammatory bowel disease: expert-based guidelines for daily practice. J Gastrointestin Liver Dis 2010;19:291-294.

5. Simsek M, Meijer B, van Bodegraven AA, de Boer NKH, Mulder CJJ. Finding hidden treasures in old drugs: the challenges and importance of licensing generics. Drug Discov Today 2018;23:17-21. doi:10.1016/j. drudis.2017.08.008

6. Zaza G, Cheok M, Krynetskaia N, et al. Thiopurine pathway. Pharmacogenet Genomics 2010;20:573-574. doi:10.1097/ FPC.0b013e328334338f

7. van Gennep S, Konte K, Meijer B, et al. Systematic review with metaanalysis: risk factors for thiopurine-induced leukopenia in IBD. Aliment Pharmacol Ther 2019;50:484-506. doi:10.1111/apt.15403

8. Meijer B, Kreijne JE, van Moorsel SAW, et al. 6-methylmercaptopurineinduced leukocytopenia during thiopurine therapy in inflammatory bowel disease patients. J Gastroenterol Hepatol 2017;32:1183-1190. doi:10.1111/jgh.13656

9. Marinaki AM, Ansari A, Duley JA, et al. Adverse drug reactions to azathioprine therapy are associated with polymorphism in the gene encoding inosine triphosphate pyrophosphatase (ITPase). Pharmacogenetics 2004;14:181-187. doi:10.1097/00008571-20040300000006

10. Colombel JF, Sandborn WJ, Reinisch W, et al. Infliximab, azathioprine, or combination therapy for Crohn's disease. N Engl J Med 2010;362:13831395. doi:10.1056/NEJMoa0904492

11. Roblin X, Williet N, Boschetti G, et al. Addition of azathioprine to the switch of anti-TNF in patients with IBD in clinical relapse with undetectable anti-TNF trough levels and antidrug antibodies: a prospective randomised trial. Gut 2020;69:1206-1212. doi:10.1136/ gutjnl-2019-319758

12. Osterman MT, Haynes K, Delzell E, et al. Effectiveness and Safety of Immunomodulators With Anti-Tumor Necrosis Factor Therapy in Crohn's Disease. Clin Gastroenterol Hepatol 2015;13:1293-1301.e5. doi:10.1016/j.cgh.2015.02.017

13. Jones JL, Kaplan GG, Peyrin-Biroulet L, et al. Effects of Concomitant Immunomodulator Therapy on Efficacy and Safety of Anti-Tumor Necrosis Factor Therapy for Crohn's Disease: A Meta-analysis of Placebo-controlled Trials. Clin Gastroenterol Hepatol 2015;13:22332240.e1-e2. doi:10.1016/j.cgh.2015.06.034

14. Kirchgesner J, Lemaitre M, Carrat F, Zureik M, Carbonnel F, DraySpira R. Risk of Serious and Opportunistic Infections Associated With Treatment of Inflammatory Bowel Diseases. Gastroenterology 2018;155:337-346.e10. doi:10.1053/j.gastro.2018.04.012

15. Toruner M, Loftus EV Jr, Harmsen WS, et al. Risk Factors for Opportunistic Infections in Patients With Inflammatory Bowel Disease. Gastroenterology 2008;134:929-936. doi:10.1053/j. gastro.2008.01.012 
16. Bots S, Gecse K, Barclay M, D'Haens G. Combination Immunosuppression in IBD. Inflamm Bowel Dis 2018;24:539-545. doi:10.1093/ibd/izx065

17. Meijer B, Seinen ML, Leijte NN, Mulder CJ, van Bodegraven AA, de Boer NK. Clinical Value of Mercaptopurine After Failing Azathioprine Therapy in Patients With Inflammatory Bowel Disease. Ther Drug Monit 2016;38:463-470. doi:10.1097/ftd.0000000000000312

18. Bowen DG, Selby WS. Use of 6-mercaptopurine in patients with inflammatory bowel disease previously intolerant of azathioprine. Dig Dis Sci 2000;45:1810-1813. doi:10.1023/a:1005569808947

19. Boulton-Jones JR, Pritchard K, Mahmoud AA. The use of 6-mercaptopurine in patients with inflammatory bowel disease after failure of azathioprine therapy. Aliment Pharmacol Ther 2000;14:15611565. doi:10.1046/j.1365-2036.2000.00872.x

20. Biemans VBC, Savelkoul E, Gabriëls RY, et al. A comparative analysis of tioguanine versus low-dose thiopurines combined with allopurinol in inflammatory bowel disease patients. Aliment Pharmacol Ther 2020;51:1076-1086. doi:10.1111/apt.15730

21. Ward MG, Patel KV, Kariyawasam VC, et al. Thioguanine in inflammatory bowel disease: Long-term efficacy and safety. United European Gastroenterol J 2017;5:563-570. doi:10.1177/2050640616663438

22. van Asseldonk DP, Seinen ML, de Boer NK, van Bodegraven AA, Mulder CJ. Hepatotoxicity associated with 6-methyl mercaptopurine formation during azathioprine and 6-mercaptopurine therapy does not occur on the short-term during 6-thioguanine therapy in IBD treatment. J Crohns Colitis 2012;6:95-101. doi:10.1016/j.crohns.2011.07.009

23. Chaparro M, Ordas I, Cabre E, et al., Safety of thiopurine therapy in inflammatory bowel disease: long-term follow-up study of 3931 patients. Inflamm Bowel Dis 2013;19:1404-1410. doi:10.1097/ MIB.0b013e318281f28f

24. Meijer B, Mulder CJ, Peters GJ, van Bodegraven AA, de Boer NK. Efficacy of thioguanine treatment in inflammatory bowel disease: A systematic review. World J Gastroenterol 2016;22:9012-9021. doi:10.3748/wjg.v22.i40.9012

25. Chande N, Patton PH, Tsoulis DJ, Thomas BS, MacDonald JK. Azathioprine or 6-mercaptopurine for maintenance of remission in Crohn's disease. Cochrane Database Syst Rev 2015;(10):CD000067. doi:10.1002/14651858.CD000067.pub3

26. Timmer A, Patton PH, Chande N, McDonald JW, MacDonald JK. Azathioprine and 6-mercaptopurine for maintenance of remission in ulcerative colitis. Cochrane Database Syst Rev 2016;2016(5):CD000478. doi: 10.1002/14651858.CD000478.pub4

27. Simsek M, Deben DS, Horjus CS, et al. Sustained effectiveness, safety and therapeutic drug monitoring of tioguanine in a cohort of 274 IBD patients intolerant for conventional therapies. Aliment Pharmacol Ther 2019;50:54-65. doi:10.1111/apt.15280

28. Sultan KS, Berkowitz JC, Khan S. Combination therapy for inflammatory bowel disease. World J Gastrointest Pharmacol Ther 2017;8:103-113. doi:10.4292/wjgpt.v8.i2.103

29. Toksvang LN, Schmidt MS, Arup S, et al. Hepatotoxicity during 6-thioguanine treatment in inflammatory bowel disease and childhood acute lymphoblastic leukaemia: A systematic review. PLoS One 2019;14:e0212157. doi:10.1371/journal.pone.0212157

30. de Boer NK, Zondervan PE, Gilissen LP, et al. Absence of nodular regenerative hyperplasia after low-dose 6-thioguanine maintenance therapy in inflammatory bowel disease patients. Dig Liver Dis 2008;40:108-113. doi:10.1016/j.dld.2007.10.013

31. Gilissen LP, Derijks LJ, Driessen A, et al. Toxicity of 6-thioguanine: no hepatotoxicity in a series of IBD patients treated with long-term, low dose 6-thioguanine. Some evidence for dose or metabolite level dependent effects? Dig Liver Dis 2007;39:156-159. doi:10.1016/j. dld.2006.10.007

32. van Asseldonk DP, Jharap B, de Boer NK, et al. 415 Liver Histology of IBD Patients Who are Treated With 6-Thioguanine Due to Failure of Conventional Thiopurines Reveals Very Few Cases of Nodular Regenerative Hyperplasia. Gastroenterology 2010;138:S62. doi:10.1016/ S0016-5085(10)60283-1

33. Dubinsky MC, Vasiliauskas EA, Singh H, et al. 6-thioguanine can cause serious liver injury in inflammatory bowel disease patients. Gastroenterology 2003;125:298-303. doi:10.1016/s0016-5085(03)00938-7

34. Ansari A, Elliott T, Fong F, et al. Further experience with the use of 6-thioguanine in patients with Crohn's disease. Inflamm Bowel Dis 2008;14:1399-1405. doi:10.1002/ibd.20492

35. Teml A, Schwab M, Hommes DW, et al. A systematic survey evaluating 6-thioguanine-related hepatotoxicity in patients with inflammatory bowel disease. Wien Klin Wochenschr 2007;119:519-526. doi:10.1007/ s00508-007-0841-0

36. Dubinsky MC, Hassard PV, Seidman EG, et al. An open-label pilot study using thioguanine as a therapeutic alternative in Crohn's disease patients resistant to 6-mercaptopurine therapy. Inflamm Bowel Dis 2001;7:181-189. doi:10.1097/00054725-200108000-00001

37. Pavlidis P, Ansari A, Duley J, Oancea I, Florin T. Splitting a therapeutic dose of thioguanine may avoid liver toxicity and be an efficacious treatment for severe inflammatory bowel disease: a 2-center observational cohort study. Inflamm Bowel Dis 2014;20:2239-2246. doi:10.1097/MIB.0000000000000206

38. Beaugerie L, Brousse N, Bouvier AM, et al. Lymphoproliferative disorders in patients receiving thiopurines for inflammatory bowel disease: a prospective observational cohort study. Lancet 2009;374:16171625. doi:10.1016/s0140-6736(09)61302-7

39. Hyams JS, Dubinsky MC, Baldassano RN, et al. Infliximab Is Not Associated With Increased Risk of Malignancy or Hemophagocytic Lymphohistiocytosis in Pediatric Patients With Inflammatory Bowel Disease. Gastroenterology 2017;152:1901-1914.e3. doi:10.1053/j. gastro.2017.02.004

40. Balfour HH Jr, Sifakis F, Sliman JA, Knight JA, Schmeling DO, Thomas W. Age-specific prevalence of Epstein-Barr virus infection among individuals aged 6-19 years in the United States and factors affecting its acquisition. J Infect Dis 2013;208:1286-1293. doi:10.1093/infdis/jit321

41. Ahmed T, Brown F, Ahmed R, Whitehead S, Steed H, Brookes MJ. P500 The effects of EBV naïve status on treatment decisions in patients with inflammatory bowel disease: Does the risk of GI lymphoma justify the cost? J Crohns Colitis 2018;12(Suppl_1):S358. doi:10.1093/ecco-jcc/ jjx180.627

42. Barnes EL, Herfarth HH. The Usefulness of Serologic Testing for Epstein-Barr Virus Before Initiation of Therapy for Inflammatory Bowel Disease. Gastroenterology 2017;153:1167. doi:10.1053/j. gastro.2017.04.055

43. Chapman S, El-Matary W. Screening for Epstein-Barr Virus Status and Risk of Hemophagocytic Lymphohistiocytosis in Children With Inflammatory Bowel Disease on Azathioprine. Gastroenterology 2017;153:1167-1168. doi:10.1053/j.gastro.2017.07.052

44. Laharie D, Vergniol J, Bioulac-Sage P, et al. Usefulness of noninvasive tests in nodular regenerative hyperplasia of the liver. Eur J Gastroenterol Hepatol 2010;22:487-493. doi:10.1097/MEG.0b013e328334098f

45. Meijer B, van Everdingen CK, Ramsoekh D, et al. Transient elastography to assess liver stiffness in patients with inflammatory bowel disease. Dig Liver Dis 2018;50:48-53. doi:10.1016/j.dld.2017.09.128 
46. Meijer B, Mulder CJ, van Bodegraven AA, de Boer NK. How I treat my inflammatory bowel disease-patients with thiopurines? World J Gastrointest Pharmacol Ther 2016;7:524-530. doi:10.4292/wjgpt. v7.i4.524

47. Simsek M, Meijer B, Mulder CJJ, van Bodegraven AA, de Boer NKH. Analytical Pitfalls of Therapeutic Drug Monitoring of Thiopurines in Patients With Inflammatory Bowel Disease. Ther Drug Monit 2017;39:584-588. doi:10.1097/FTD.0000000000000455

48. Shipkova M, Armstrong VW, Wieland E, Oellerich M., Differences in nucleotide hydrolysis contribute to the differences between erythrocyte 6-thioguanine nucleotide concentrations determined by two widely used methods. Clin Chem 2003;49:260-268. doi:10.1373/49.2.260

49. Dubinsky MC, Feldman EJ, Abreu MT, Targan SR, Vasiliauskas EA. Thioguanine: a potential alternate thiopurine for IBD patients allergic to 6-mercaptopurine or azathioprine. Am J Gastroenterol 2003;98:10581063.

50. Herrlinger KR, Fellermann K, Fischer C, et al. Thioguaninenucleotides do not predict efficacy of tioguanine in Crohn's disease. Aliment Pharmacol Ther 2004;19:1269-1276. doi:10.1111/j.13652036.2004.01947.x

51. Lancaster DL, Patel N, Lennard L, Lilleyman JS. Leucocyte versus erythrocyte thioguanine nucleotide concentrations in children taking thiopurines for acute lymphoblastic leukaemia. Cancer Chemother Pharmacol 2002;50:33-36. doi:10.1007/s00280-002-0442-6

52. de Boer NK, de Graaf P, Wilhelm AJ, Mulder CJ, van Bodegraven AA. On the limitation of 6-tioguaninenucleotide monitoring during tioguanine treatment. Aliment Pharmacol Ther 2005;22:447-451. doi:10.1111/j.1365-2036.2005.02581.x

53. Meijer B, Wilhelm AJ, Mulder CJJ, Bouma G, van Bodegraven AA, de Boer NKH. Pharmacology of Thiopurine Therapy in Inflammatory Bowel Disease and Complete Blood Cell Count Outcomes: A 5-Year Database Study. Ther Drug Monit 2017;39:399-405. doi:10.1097/ ftd.0000000000000414

54. de Hoogd S, Wong DR, de Vries DR, Harmsze AM. Severe pancytopenia and aspergillosis caused by thioguanine in a thiopurine S-methyltransferase deficient patient: a case report. Eur J Gastroenterol Hepatol 2019;31:1592-1596. doi:10.1097/meg.0000000000001504

55. McBride KL, Gilchrist GS, Smithson WA, Weinshilboum RM, Szumlanski CL. Severe 6-thioguanine-induced marrow aplasia in a child with acute lymphoblastic leukemia and inherited thiopurine methyltransferase deficiency. J Pediatr Hematol Oncol 2000;22:441-445. doi:10.1097/00043426-200009000-00011

56. Lennard L. TPMT in the treatment of Crohns disease with azathioprine. Gut 2002;51:143-146. doi:10.1136/gut.51.2.143

57. Colombel JF, Ferrari N, Debuysere H, et al. Genotypic analysis of thiopurine S-methyltransferase in patients with Crohn's disease and severe myelosuppression during azathioprine therapy. Gastroenterology 2000;118:1025-1030. doi:10.1016/s0016-5085(00)70354-4

58. Sluiter RL, Van Marrewijk C, De Jong D, et al. Genotype-Guided Thiopurine Dosing Does not Lead to Additional Costs in Patients With Inflammatory Bowel Disease. J Crohns Colitis 2019;13:838-845. doi:10.1093/ecco-jcc/jjz009

59. Kanis SL, de Lima-Karagiannis A, de Boer NKH, van der Woude CJ. Use of Thiopurines During Conception and Pregnancy Is Not Associated With Adverse Pregnancy Outcomes or Health of Infants at One Year in a Prospective Study. Clin Gastroenterol Hepatol 2017;15:1232-1241. e1. doi:10.1016/j.cgh.2017.02.041

60. Akbari M, Shah S, Velayos FS, Mahadevan U, Cheifetz AS. Systematic review and meta-analysis on the effects of thiopurines on birth outcomes from female and male patients with inflammatory bowel disease. Inflamm Bowel Dis 2013;19:15-22. doi:10.1002/ibd.22948

61. Jharap B, de Boer NK, Stokkers P, et al. Intrauterine exposure and pharmacology of conventional thiopurine therapy in pregnant patients with inflammatory bowel disease. Gut 2014;63:451-457. doi:10.1136/ gutjnl-2012-303615

62. van den Berg SA, de Boer M, van der Meulen-de Jong AE, et al. Safety of Tioguanine During Pregnancy in Inflammatory Bowel Disease. J Crohns Colitis 2016;10:159-165. doi:10.1093/ecco-jcc/jjv189

63. Dubinsky MC, Lamothe S, Yang HY, et al. Pharmacogenomics and metabolite measurement for 6-mercaptopurine therapy in inflammatory bowel disease. Gastroenterology 2000;118:705-713. doi:10.1016/s00165085(00)70140-5

64. Seiderer J, Zech CJ, Reinisch W, et al. A multicenter assessment of liver toxicity by MRI and biopsy in IBD patients on 6-thioguanine. J Hepatol 2005;43:303-309. doi:10.1016/j.jhep.2005.02.051

65. De Boer NK, Tuynman H, Bloemena E, et al. Histopathology of liver biopsies from a thiopurine-naive inflammatory bowel disease cohort: prevalence of nodular regenerative hyperplasia. Scand J Gastroenterol 2008;43:604-608. doi:10.1080/00365520701800266

66. Hartleb M, Gutkowski K, Milkiewicz P. Nodular regenerative hyperplasia: evolving concepts on underdiagnosed cause of portal hypertension. World J Gastroenterol 2011;17:1400-1409. doi:10.3748/ wjg.v17.i11.1400

67. Vernier-Massouille G, Cosnes J, Lemann M, et al. Nodular regenerative hyperplasia in patients with inflammatory bowel disease treated with azathioprine. Gut 2007;56:1404-1409. doi:10.1136/gut.2006.114363

68. van Asseldonk DP, Jharap B, Verheij J, et al. The Prevalence of Nodular Regenerative Hyperplasia in Inflammatory Bowel Disease Patients Treated with Thioguanine Is Not Associated with Clinically Significant Liver Disease. Inflamm Bowel Dis 2016;22:2112-2220. doi:10.1097/ mib.0000000000000869

69. Meijer B, Simsek M, Blokzijl H, et al. Nodular regenerative hyperplasia rarely leads to liver transplantation: A 20-year cohort study in all Dutch liver transplant units. United European Gastroenterol J 2017;5:658-667. doi: $10.1177 / 2050640616680550$

70. van Asseldonk DP, Simsek M, de Boer NKH, et al. Limited relevance and progression of histological alterations in the liver during thioguanine therapy in inflammatory bowel disease patients. Scand J Gastroenterol 2019;54:753-760. doi:10.1080/00365521.2019.1629006

71. Simsek M, Meijer B, Ramsoekh D, et al. Clinical Course of Nodular Regenerative Hyperplasia in Thiopurine Treated Inflammatory Bowel Disease Patients. Clin Gastroenterol Hepatol 2019;17:568-570. doi:10.1016/j.cgh.2018.05.009

72. Ferlitsch A, Teml A, Reinisch W, et al. 6-thioguanine associated nodular regenerative hyperplasia in patients with inflammatory bowel disease may induce portal hypertension. Am J Gastroenterol 2007;102:2495503.

73. Kotlyar DS, Lewis JD, Beaugerie L, et al. Risk of lymphoma in patients with inflammatory bowel disease treated with azathioprine and 6-mercaptopurine: a meta-analysis. Clin Gastroenterol Hepatol 2015;13:847-858.e4. doi:10.1016/j.cgh.2014.05.015

74. Ariyaratnam J, Subramanian V. Association between thiopurine use and nonmelanoma skin cancers in patients with inflammatory bowel disease: a meta-analysis. Am J Gastroenterol 2014;109:163-169. doi:10.1038/ajg.2013.451

75. Yuan B, O'Connor TR, Wang Y. 6-Thioguanine and $S^{6}$-methylthioguanine are mutagenic in human cells. ACS Chem Biol 2010;5:1021-1027. doi:10.1021/cb100214b 
76. Annese V, Beaugerie L, Egan L, et al. European Evidence-based Consensus: Inflammatory Bowel Disease and Malignancies. J Crohns Colitis 2015;9:945-965. doi:10.1093/ecco-jcc/jjv141

77. Movva R, Lobb M, Ó Cuív P, Florin THJ, Duley JA, Oancea I. Microbial metabolism of thiopurines: A method to measure thioguanine nucleotides. J Microbiol Methods 2016;128:102-107. doi:10.1016/j. mimet.2016.07.017
78. Oancea I, Movva R, Das I, et al. Colonic microbiota can promote rapid local improvement of murine colitis by thioguanine independently of T lymphocytes and host metabolism. Gut 2017;66:59-69. doi:10.1136/ gutjnl-2015-310874

79. Florin THJ, Wright JD, Jambhrunkar SD, Henman MG, Popat A. A well-tolerated and rapidly acting thiopurine for IBD? Drug Discov Today 2019;24:37-41. doi:10.1016/j.drudis.2018.09.001 